\title{
A Clinical Study on the Incidence and Visual Outcome after Surgical Management of Lens-Induced Glaucoma
}

\author{
Jyoti Bhuyan', Pranoya Baishyakh² \\ ${ }^{1,2}$ Regional Institute of Ophthalmology, Gauhati Medical College and Hospital, Guwahati, Assam, India.
}

Corresponding Author: Pranoya Baishyakh

\begin{abstract}
Aims and Objectives: To determine 1) the incidence of lens-induced glaucoma. 2) the more prevalent type of LIG. and 3) Visual outcome following surgical management of LIG.

Material and Methods: 50 patients of lensinduced glaucoma, who presented in OPD of Regional Institute of Ophthalmology, were included in the study. All patients were admitted and managed in indoor wards. Informed and written consents were taken. A detailed history and a thorough ocular examination was done. Surgical correction was done by SICS or Phacoemulsification or triple procedures operations.
\end{abstract}

Results: A standardized proforma was used to compile data and it was analyzed statistically using Chi-square test and Probability value. The incidence of LIG was found to be 0.174 among all OPD attendees. Phacomorphic glaucoma (58\%) was found to be the highest followed by phacolytic glaucoma (32\%). No significant association with respect to sex and age of the cases was found. The presenting symptoms varied in severity and were directly proportional to the degree of rise of IOP. $38 \%$ of cases in our study achieved best corrected visual acuity of 6/9 and 28\% achieved 6/12 acuity at the end of 6 weeks. Visual outcome was found to be better for cases with early detection and treatment.

Conclusion: The mainstay to prevent and treat LIG is early diagnosis and treatment of cataract. Delayed treatment of LIG may result in poor visual outcome.

Keywords: LIG, IOP, Phacomorphic glaucoma, Phacolytic glaucoma, SICS,

Phacoemulsification.

\section{INTRODUCTION}

Glaucoma is a diverse group of eye diseases with a multifactorial etiology characterized by an acquired loss of retinal ganglion cells, progressive optic neuropathy with morphological abnormalities in the optic nerve head and visual field defect, in which raised intraocular pressure (IOP) is a major and only modifiable risk factor ${ }^{1}$.

Glaucoma dates back to as early as 400 BC. Hippocratic writings are testimony to this where it is mentioned as 'glaucosis' although it included other blinding conditions including cataract ${ }^{2}$

Glaucoma is considered as a lifelong disease and is a leading cause of irreversible but preventable blindness. As a developing country, the main causes of blindness in India are as follows: cataract (62.60\%), refractive error (19.70\%), corneal blindness (0.90\%), glaucoma (5.80\%), surgical complications $(1.20 \%)$, posterior capsular opacification $(0.90 \%)$, posterior segment disorder $(4.70 \%)$ and others $(4.19 \%)^{3}$. It has been reported that glaucoma affects the quality of life to a greater degree in India than in the west ${ }^{3}$. Population based studies suggest that more than $90 \%$ of glaucoma cases in the country remain undiagnosed. This is in contrast to $40-60 \%$ rates of undiagnosed disease in more developed countries $^{4-8}$. Glaucoma, although more commonly affects older adults above 40 years, it can occur in all age groups and all strata of the society making it a major public health problem with significant health and economic consequences. Nearly one fifth of 
population affected by glaucoma become blind in one or both eyes ${ }^{9}$. The prevalence of glaucoma is higher in urban areas as compared to rural. Life style changes and higher rate of diabetes and cardiovascular diseases may contribute to the increased prevalence of glaucoma in urban area ${ }^{9}$.

But the major area of concern is that vast majority $(90 \%)$ of cases of glaucoma remain undiagnosed because of

- Unawareness on the part of population affected by glaucoma

- Missed diagnosis at primary care level due to lack of comprehensive eye examination

- Misdiagnosed even at tertiary care

So, by improving the standard of ophthalmic examination through gonioscopy and optic disc evaluation we can reduce the incidence of glaucoma to a huge extent. Among the various risk factors, increased intra-ocular pressure (IOP) is the most frequent and modifiable causative risk factor for glaucoma.

About 60 types of glaucoma are known. Classical characteristics of glaucomas are ${ }^{10}$ :

1. Abnormality of the anterior portion of the eye that results in increased IOP

2. Loss of retinal ganglion cells in a distribution that suggests the injury occurred at the optic nerve head (ONH)

3. Nerve fibre layer loss which corresponds to the pattern of visual field loss.

Lens induced glaucoma (LIG) is a special type of secondary glaucoma and is an ophthalmic emergency. In many cases, the crystalline lens may be associated with glaucoma if dislocated either due to trauma or certain inherited disorders. In many instances, cataractous lens is found in relation to glaucoma. In the year 1900 Gifford and Von Reuss first described lens induced glaucoma in relation to cataract ${ }^{11}$. Since then various lens induced glaucomas has been reported and studied. The crystalline lens is implicated as a causative element in producing several forms of glaucoma. A cataractous lens may lead to glaucoma by obstruction of trabecular meshwork with protein and macrophages (i.e. phacolytic glaucoma), lens particles and debris (i.e. lens particle glaucoma) or inflammatory cells as a part of immune response to lens protein antigen (phacoanaphylactic glaucoma). A swollen or intumescent lens may also lead to pupillary block and secondary angle closure glaucoma (phacomorphic glaucoma) 2,12,13.

There is cataract detection and management backlog of around 12 million in India ${ }^{14}$ which is annually increasing at an estimated rate of 3.8 million $^{15}$. This huge backlog of ever increasing cataract is due to increased life expectancy, rapidly growing ageing population and disparity between rate of new cases and rate of surgical removal; hence the occurrence of lens induced glaucoma in India has high probability $^{16}$

\section{MATERIAL AND METHODS}

The present study was conducted on the patients attending the outpatient department of the Regional Institute of Ophthalmology, Guwahati Medical College and Hospital, Guwahati, who were diagnosed with lens-induced glaucoma. The study was conducted for a period of 1 year from June 2020 to May 2021. All patients were admitted in the indoor wards of ophthalmology department. Informed and written consents in their own language were taken before including them in the study.

All cases diagnosed with lens induced glaucoma irrespective of age, sex and clinical types were interrogated, clinically investigated and managed.

Inclusion criteria: cases were clinically diagnosed into various types of LIG such as phacomorphicglaucoma, phacolytic glaucoma, lens particle glaucoma, glaucoma secondary to ectopia lentis/lens displacement glaucoma or phacotopic galucoma and phacoanaphylactic glaucoma.

Exclusion criteria include cases of primary open angle glaucoma, lens induced 
Jyoti Bhuyan et.al. A clinical study on the incidence and visual outcome after surgical management of lensinduced glaucoma.

glaucoma with previous posterior segment pathology, corneal scarring or opacity which would hamper evaluation of visual outcome and other cases of secondary glaucoma.

\section{Patient evaluation:}

Patient evaluation was done by detailed history including history of trauma, past history suggestive of uveitis, history of surgeries in the fellow eye etc. A detailed clinical examination including visual acuity, tonometry, slit lamp examination, gonioscopy was done of both eyes. Biometry with IOL power calculation of affected eye was done wherever possible. Bscan of the affected eye to visualise the fundus was done to rule out posterior segment pathology. Best corrected visual acuity was recorded at the time of presentation and at 6 weeks using Snellen's chart, Landolt $\mathrm{C}$ chart and $\mathrm{E}$ chart. Other pre-operative tests like syringing of nasolacrimal duct, blood pressure measurement was done routinely.

A detailed systemic examination was done of all cases to rule out any systemic disease.

\section{Laboratory investigations include}

1. Blood investigation TLC, DLC, ESR, haemoglobin, RBS, Se Creatinine

2. R/E urine

3. CXR

4. ECG

\section{MANAGEMENT:}

Medical management: All cases of lens induced glaucoma were admitted in the hospital and were first managed by medical therapy. The aim was to bring the raised IOP down and relief the pain. Along with these, aim was also to subside the uveal inflammation prior to surgical management. Anti-glaucoma drugs like beta-blocker (timolol maleate 0.5\%), topical carbonic anhydrase inhibitors Dorzolamide in combination with Timolol maleate, oral carbonic anhydrase inhibitors (Tablet Acetazolamide 250mg), hyperosmotic agents like Mannitol (20\%), Glycerol, topical steroid either Prednisolone acetate(1\%) or Dexamethasone-antibiotic combination drops were used to bring down inflammation. Nd-YAG laser iridotomy was done in 1 case of angle closure with pupillary block with presence of peripheral anterior synechiae in which medical management failed to decrease the IOP.

Surgical management: Manual Small Incision Cataract Surgery (SICS) with PCIOL implantation was the preferred surgery. Suitable modifications were made according to the situation encountered. In some cases triple procedure i.e. SICS with PCIOL with trabeculectomy had to be performed as IOP was not responding with medical management. Also triple procedure was performed in cases with late presentation (>7days of symptoms) and peripheral anterior synechiae.

All patients were given topical antibiotic steroid combination drops and a short acting cycloplegic drop post operatively. Systemic steroid was given where indicated. Follow up of all the patients were done on $1^{\text {st }}$ post-op day, at 2 weeks and 6 weeks. Best corrected visual acuity (BCVA) was recorded and required spectacle correction was prescribed at 6 weeks.

\section{RESULTS AND OBSERVATION}

A total number of 50 LIG cases were included in the study who presented to the OPD of Regional Institute of Ophthalmology (RIO, GMCH) during the period from June 2020 to May 2021.

\section{INDICENCE:}

TABLE 1: Incidence and occurrence of lens induced glaucoma

\begin{tabular}{|l|l|}
\hline $\begin{array}{l}\text { Total number of cases attending OPD in RIO, } \\
\text { GMCH }\end{array}$ & 28735 \\
\hline Total number of LIG cases & 50 \\
\hline Incidence & 0.174 \\
\hline
\end{tabular}

Hence the incidence of lens induced glaucoma is 0.174 . In all the 50 cases of LIG, a cataractous lens is found to be the cause of rise in IOP. 
Jyoti Bhuyan et.al. A clinical study on the incidence and visual outcome after surgical management of lensinduced glaucoma.

TABLE 2: TYPES OF LENS INDUCED GLAUCOMA

\begin{tabular}{|l|l|l|}
\hline DIAGNOSIS & Frequency & \% \\
\hline LENS PARTICLE TYPE & 3 & 6 \\
\hline PHACOLYTIC & 16 & 32 \\
\hline PHACOMORPHIC & 29 & 58 \\
\hline PHACOANAPHYLACTIC & 2 & 4 \\
\hline TOTAL & 50 & 100 \\
\hline
\end{tabular}

In this study we have found that, the most prevalent type of glaucoma was phacomorphic (29 cases, i.e. 58\%) followed by phacolytic glaucoma (16 cases, i.e. $32 \%$ ). 3 cases were found to be of lens particle glaucoma and 2 cases of phacoanaphylactic glaucoma.

TABLE 3: SEX DISTRIBUTION

\begin{tabular}{|l|l|l|}
\hline Sex & Frequency & Percent \\
\hline Male & 21 & 42 \\
\hline Female & 29 & 58 \\
\hline Total & 50 & 100 \\
\hline
\end{tabular}

The study revealed a higher incidence of lens induced glaucoma in female (58\%) than males(42\%).

TABLE 4: AGE DISTRIBUTION

\begin{tabular}{|l|l|l|}
\hline Age_Group & Frequency & Percent \\
\hline $39-55$ & 12 & 24 \\
\hline $56-70$ & 31 & 62 \\
\hline$>70$ & 7 & 14 \\
\hline Total & 50 & 100 \\
\hline
\end{tabular}

In this study we found that, highest number of affected individuals were in the age group of 56-70years (62\%). Mean age of affected individuals is 61.540 year.

TABLE 5: STATISTICAL VALUES IN RELATION TO AGE

\begin{tabular}{|l|l|}
\hline \multicolumn{1}{|c|}{} & AGE \\
\hline Mean & 61.540 \\
\hline Std. Error of Mean & 1.238 \\
\hline Median & 61.500 \\
\hline Std. Deviation & 8.753 \\
\hline Minimum & 39.000 \\
\hline Maximum & 86.000 \\
\hline 95\%CI & $59.05-64.03$ \\
\hline
\end{tabular}

In our study, 26 cases (52\%) had right eye affected whereas 24 cases (48\%) had their left eye affected. Hence no clinical significance was observed on the laterality of eye affected.

\section{PRESENTING SIGNS AND SYMPTOMS}

The presenting signs varied considerably with individuals and were directly proportional to the rise in IOP. Patients chiefly complained of diminution of vision with pain and redness of affected eye. Uniocular presentation was noticed. Patients generally gave a history of gradual diminution of vision with a sudden acute attack of severe pain and redness in one eye.

Table 6: PRESENTING SYMPTOMS

\begin{tabular}{|l|l|l|}
\hline \multicolumn{1}{|c|}{ SYMPTOMS } & NO OF PATIENTS & $\mathbf{\%}$ \\
\hline SWELLING OF LIDS & 24 & 48 \\
\hline DIMINUTION OF VISION & 50 & 100 \\
\hline EYE PAIN & 50 & 100 \\
\hline REDNESS OF EYE & 46 & 92 \\
\hline HEADCHE & 43 & 86 \\
\hline VOMITTING & 9 & 18 \\
\hline WATERING & 17 & 34 \\
\hline
\end{tabular}

In our study $100 \%$ of cases presented with diminution of vision and eye pain. $92 \%$ of cases complained of redness of eye followed by headache (86\%).

TABLE 7: PRESENTING SIGNS

\begin{tabular}{|l|l|l|l|}
\hline Number & Signs & $\begin{array}{l}\text { No Of } \\
\text { Patients }\end{array}$ & Percentage\% \\
\hline 1$)$ & $\begin{array}{l}\text { Circumcorneal } \\
\text { congestion }\end{array}$ & 50 & $100 \%$ \\
\hline 2$)$ & $\begin{array}{l}\text { Corneal } \\
\text { edema }\end{array}$ & 50 & $100 \%$ \\
\hline 3$)$ & AC reaction & 49 & $98 \%$ \\
\hline 4$)$ & Shallow AC & 29 & $58 \%$ \\
\hline 5$)$ & $\begin{array}{l}\text { Mid-dilated } \\
\text { pupil }\end{array}$ & 50 & $100 \%$ \\
\hline 6$)$ & Fundus visible & 50 & $100 \%$ \\
\hline 7$)$ & $\begin{array}{l}\text { Gonioscopic } \\
\text { angle closed }\end{array}$ & 31 & $62 \%$ \\
\hline
\end{tabular}

All patients were diagnosed with circumcorneal congestion, corneal edema, mid-dilated pupil and no fundus visibility. $49 \%$ patients had AC reaction and $62 \%$ had closed angles on gonioscopy.

Table 8: Duration of symptoms
\begin{tabular}{|l|l|l|}
\hline $\begin{array}{l}\text { DURATION OF } \\
\text { SYMPTOMS }\end{array}$ & FREQUENCY & PERCENTAGE \\
\hline$<$ 7 Days & 28 & 56 \\
\hline 1-2 week & 16 & 32 \\
\hline 2-4 week & 4 & 8 \\
\hline$>=4$ week & 2 & 4 \\
\hline Total & 50 & 100 \\
\hline
\end{tabular}

In this study, most cases (56\%) presented within 7 days from onset of symptoms and 32\% cases presented within 2 weeks of onset of symptoms.

Table 9: IOP AT PRESENTATION

\begin{tabular}{|l|l|l|}
\hline IOP & Frequency & Percent \\
\hline $20-30(\mathrm{~mm}$ of $\mathrm{Hg})$ & 3 & 6 \\
\hline $31-40(\mathrm{~mm}$ of $\mathrm{Hg})$ & 15 & 30 \\
\hline$>40(\mathrm{~mm}$ of $\mathrm{Hg})$ & 32 & 64 \\
\hline Total & 50 & 100 \\
\hline
\end{tabular}


Jyoti Bhuyan et.al. A clinical study on the incidence and visual outcome after surgical management of lensinduced glaucoma.

Here majority of cases presented 30\%, presented with IOP within 31with IOP $>40 \mathrm{mmHg}(64 \%) .15$ cases i.e. $40 \mathrm{mmHg}$.

TABLE 10: IOP DISTRIBUTION AT PRE-OP, IMMEDIATE POST-OP AND AT 6 WEEKS

\begin{tabular}{|l|l|l|}
\hline & Mean & p value \\
\hline IOP & $43.84 \pm 9.93$ & \\
\cline { 1 - 2 }$<0$ RREOP IOP & $27.12 \pm 4.52$ & \multirow{2}{*}{$<0.001$} \\
\cline { 1 - 2 } IMMEDIATE POST OP IOP & $17.82 \pm 2.75$ \\
\cline { 1 - 2 } 6 WEEK POST OP IOP & $15.90 \pm 2.46$ & \\
\hline
\end{tabular}

\begin{tabular}{|l|l|l|l|l|}
\hline & IOP & PREOP IOP & IMMEDIATE POST OP IOP & 6 WEEK POST OP POST OP IOP \\
\hline Mean & 43.84 & 27.12 & 17.82 & 15.90 \\
\hline Std. Deviation & 9.93 & 4.52 & 2.75 & 2.46 \\
\hline Std. Error of Mean & 1.40 & 0.64 & 0.39 & 0.35 \\
\hline Median & 44.50 & 28.00 & 18.00 & 16.00 \\
\hline Minimum & 22.00 & 15.00 & 14.00 & 10.00 \\
\hline Maximum & 69.00 & 36.00 & 23.00 & 21.00 \\
\hline
\end{tabular}

The mean IOP PRE-OP was found to be 43.84mmHg with highest IOP recorded was $69 \mathrm{mmHg}$.

Table 11: PRESENTING IOP IN DIFFERENT TYPES OF LIG

\begin{tabular}{|l|l|l|l|l|l|l|}
\hline & IOP & & & & \\
\hline DIAGNOSIS & $\mathbf{2 0 - 3 0}(\mathbf{m m}$ of $\mathbf{~ H g})$ & $\mathbf{3 1 - 4 0}(\mathbf{m m}$ of $\mathbf{~ H g})$ & $\mathbf{> 4 0}(\mathbf{m m} \mathbf{~ o f ~ H g})$ & Total & Chi & p value \\
\hline Phacomorphic & 0 & 12 & 17 & 29 & & \\
\hline Phacolytic & 3 & 3 & 10 & 16 & 10.951 & 0.09 \\
\hline Lens particle type & 0 & 0 & 3 & 3 & & \\
\hline Phacoanaphylactic & 0 & 0 & 2 & 2 & & \\
\hline Total & 3 & 32 & 50 & & \\
\hline
\end{tabular}

$P V A L U E=0.09$. Here we found that the relation between the presenting IOP and different types of LIG is not statiscally significant.

In this study, majority of cases had IOP $>40 \mathrm{mmHg}$ at presentation in both phacomorphic and phacolytic glaucoma. Only a total of 3 cases presented with IOP $<30 \mathrm{mmHg}$.

\section{VISUAL ACUITY}

Presenting vision was affected to hand movement close to face (HMCF) to perception of light $\left(\mathrm{PL}^{+}\right)$.
TABLE 12: VISUAL ACUITY OF AFFECTED EYE AT PRESENTATION

\begin{tabular}{|l|l|l|}
\hline Vision A/E & Frequency & Percent \\
\hline HMCF & 32 & 64 \\
\hline PL + & 16 & 32 \\
\hline PL $+/-$ & 2 & 4 \\
\hline Total & 50 & 100 \\
\hline
\end{tabular}

Cases presented with poor vision of hand movement close to face to perception of light. Few cases also presented with doubtful perception of light.

TABLE 13: STATUS OF THE LENS IN PHACOMORPHIC AND PHACOLYTIC GLAUCOMA CASES OF AFFECTED EYE

\begin{tabular}{|l|l|l|l|l|l|}
\hline & & DIAGNOSIS & & & \\
\hline LENS & lens particle type & Phacolytic & phacomorphic & Phacoanaphylactic & Total \\
\hline DL & 0 & 0 & 2 & 0 & 2 \\
\hline HM & 1 & 12 & 4 & 0 & 9 \\
\hline IN CAT & 1 & 2 & 21 & 2 & 34 \\
\hline MAT CAT & 1 & 2 & 2 & 0 & 5 \\
\hline Total & 3 & 16 & 29 & 2 & 50 \\
\hline
\end{tabular}

Majority of the phacomorphic LIG cases had intumescent cataract (IN CAT) i.e. 21 cases. And majority of phacolytic
LIG cases had hypermature cataract (HM) i.e 12 cases.

\section{MANAGEMENT AND ITS RESPONSES}

TABLE 14: SURGICAL PROCEDURE

\begin{tabular}{|l|l|l|l|l|l|}
\hline SURGICAL PROCEDURE & lens particle type & phacolytic & Phacomorphic & Phacoanaphylactic & Total \\
\hline SICS+PCIOL & 2 & 12 & 16 & 2 & 31 \\
\hline SICS+PCIOL+I & 0 & 1 & 5 & 0 & 6 \\
\hline TRIPLE PROCEDURE & 1 & 3 & 8 & 0 & 13 \\
\hline Total & 3 & 16 & 29 & 2 & 50 \\
\hline
\end{tabular}


Jyoti Bhuyan et.al. A clinical study on the incidence and visual outcome after surgical management of lensinduced glaucoma.

In this study we found that small incision cataract surgery with post capsular IOL implantation is the mainstay treatment with resultant decrease in IOP in all forms of LIGs.

TABLE 15: IMMEDIATE POST-OP IOP

\begin{tabular}{|l|l|l|l|l|l|}
\hline IMMEDIATE POST OP IOP & Phacomorphic & Phacolytic & lens particle type & Phacoanaphylactic & Total \\
\hline$<20 \mathrm{~mm} \mathrm{Hg}$ & 24 & 12 & 3 & 2 & 41 \\
\hline$>20 \mathrm{~mm} \mathrm{Hg}$ & 5 & 4 & 0 & 0 & 9 \\
\hline Total & 29 & 16 & 3 & 2 & 50 \\
\hline
\end{tabular}

Here we found that a total of 41 patients experienced IOP $<20 \mathrm{mmHg}$ immediately post op and only 9 cases had IOP> 20mmHg immediate post-op

\section{VISUAL OUTCOME}

\begin{tabular}{|c|c|c|c|c|c|}
\hline & \multicolumn{2}{|c|}{ POST OP VD } & \multicolumn{2}{|c|}{ BCVA $6{ }^{\mathrm{TH}}$ WEEK } & \multirow{2}{*}{$\begin{array}{c}\text { p value } \\
<0.001\end{array}$} \\
\hline & Frequency & Percent & Frequency & Percent & \\
\hline $6 / 6$ & 0 & $0.00 \%$ & 3 & $6.00 \%$ & \\
\hline $6 / 9$ & 0 & $0.00 \%$ & 19 & $38.00 \%$ & \\
\hline $6 / 12$ & 3 & $6.00 \%$ & 14 & $28.00 \%$ & \\
\hline $6 / 18$ & 6 & $12.00 \%$ & 5 & $10.00 \%$ & \\
\hline $6 / 24$ & 8 & $16.00 \%$ & 4 & $8.00 \%$ & \\
\hline $6 / 36$ & 9 & $18.00 \%$ & 4 & $8.00 \%$ & \\
\hline $6 / 60$ & 15 & $30.00 \%$ & 1 & $2.00 \%$ & \\
\hline FC AT 1M & 3 & $6.00 \%$ & 0 & $0.00 \%$ & \\
\hline FC AT 3M & 1 & $2.00 \%$ & 0 & $0.00 \%$ & \\
\hline FC ATB 4M & 1 & $2.00 \%$ & 0 & $0.00 \%$ & \\
\hline HMCF & 4 & $8.00 \%$ & 0 & $0.00 \%$ & \\
\hline Total & 50 & $100.00 \%$ & 50 & $100.00 \%$ & \\
\hline
\end{tabular}

The post-op vision and the BCVA at $6^{\text {th }}$ week varied considerably in our study.

\begin{tabular}{|c|c|c|c|c|c|c|}
\hline & \multicolumn{3}{|l|}{ BCVA } & & & \\
\hline IOP & 6/6-6/12 (Good Vision) & $>6 / 18$ (Poor Vision) & Total & OR & 95\%CI & p value \\
\hline$<40 \mathrm{~mm} \mathrm{Hg}$ & $14(82.4)$ & $3(17.6)$ & $17(100)$ & & & \\
\hline$>40 \mathrm{~mm} \mathrm{Hg}$ & $22(66.7)$ & $11(33.3$ & $33(100)$ & 2.33 & $0.552-9.866$ & 0.242 \\
\hline Total & $36(72)$ & $14(28)$ & $50(100)$ & & & \\
\hline
\end{tabular}

82.4\% (14 cases) of cases with IOP $<40 \mathrm{mmHg}$ had good vision post-op i.e. 6/6-6/12. Whereas 66.7\%(22cases) cases had poor vision post-op i.e. > 6/18.

TABLE 18 : FINAL BCVA IN RELATION TO AGE

\begin{tabular}{|l|l|l|l|l|l|l|}
\hline & \multicolumn{2}{|l|}{ BCVA } & & & \\
\hline Age Group & $\mathbf{6 / 6 - 6 / 1 2}$ (Good Vision) & $>\mathbf{6 / 1 8}$ (Poor Vision) & Total & OR & $\mathbf{9 5 \% C I}$ & p value \\
\hline$<50$ Years & $4(80)$ & $1(20)$ & $5(100)$ & & & \\
\hline$>50$ years & $32(71.1)$ & $13(28.9)$ & $45(100)$ & 1.625 & $0.166-15.963$ & 0.675 \\
\hline Total & $36(72)$ & $14(28)$ & $50(100)$ & & & \\
\hline
\end{tabular}

$80 \%$ cases with $<50$ years of age had good vision post op whereas $71 \%$ cases with $>$ 50 years had good vision post op.

TABLE 19: FINAL BCVA IN RELATION TO DURATION OF DISEASE

\begin{tabular}{|l|l|l|l|l|l|l|}
\hline & \multicolumn{2}{|c|}{ BCVA } & & & & \\
\hline DURATION & $\mathbf{6 / 6 - 6 / 1 2}($ Good Vision) & $>$ 6/18 (Poor Vision) & Total & OR & $\mathbf{9 5 \% ~ C I ~}$ & p value \\
\hline$<7$ & $24(85.7)$ & $4(14.2)$ & $28(100)$ & & & \\
\hline$>7$ & $12(54.5)$ & $10(45.4)$ & $22(100)$ & 5.00 & $1.295-19.31$ & 0.0148 \\
\hline Total & $36(72)$ & $14(28)$ & $50(100)$ & & & \\
\hline
\end{tabular}

In this study we found that good post-op vision was proportional to shorter duration between onset of symptoms and management. 
Jyoti Bhuyan et.al. A clinical study on the incidence and visual outcome after surgical management of lensinduced glaucoma.

\section{DISCUSSION}

The study was carried out on 50 cases of lens induced glaucoma (LIG) who were admitted and treated in Regional Institute of Ophthalmology, Guwahati, GMCH.

It is a longitudinal study undertaken to outline the different characteristics of lens induced glaucoma along with its risk factors and its effect on post-operative visual acuity, IOP and following manual SICS operation.

The patients were followed up from their time of admission and managed in the ward. These patients were followed upto 6 weeks post-operatively and the factors influencing the final visual outcome were studied.

Statistically Chi-Square test(x) and Probability values (p) were used and $\mathrm{p}=<0.05$ is considered statistically significant.

\section{INCIDENCE:}

In this study, the incidence of lensinduced glaucoma is $0.174 \%$ (Table no.1) out of the total cases attending outpatient department during the period of one year. The incidence of LIG in our study is marginally less but comparable to the observation by Saikia $\mathrm{AK}^{17}$ in a study conducted in the same institute. It is also much lower than that of previous report by Dutta et $\mathrm{al}^{23}$. This relatively lower incidence is most probably due to the effective implementation of the National Programme for Control of Blindness under which multiple eye camps to detect eye diseases (mostly cataract and refractive error) are being conducted round the year in the catchment area of the RIO,GMCH.

Also due to the ongoing COVID 19 pandemic, the influx of patients to the hospital OPDs have reduced to a great extent owing to lockdowns and similar inconveniences.

\section{DIAGNOSIS:}

In our study (Table 2), it is observed that the most frequent type of LIG was
Phacomorphic glaucoma (58\%) followed by Phacolytic glaucoma (32\%). Similar occurrence was noted by Pradhanet al. ${ }^{24}$ (72\%), Rijal $\mathrm{AP}^{25}(65 \%)$ and Murty et $\mathrm{al}^{22}$ (62\%)

Hence occurrence of various lensinduced glaucomas in the above studies show variations but phacomorphic glaucoma has been the commonest among all the studies including our study. Lens particle glaucoma and phacoanaphylactic glaucoma constituted the remaining $10 \%$. No cases of glaucoma due to subluxation/dislocation of lens were found in our study. It is seen that phacomorphic and phacolytic glaucoma were seen commonly in association with intumescent and hypermature cataract [Table 13]. This solidifies the importance of early detection and treatment of cataract.

\section{SEX DISTRIBUTION:}

In this study, females seemed to have an increased risk of having LIG compared to males with a ratio of $1.3: 1$. It was observed that that the majority (58\%) of cases occurred among females and 42\% cases occurred in males. In this study $\mathrm{p}=0.25$; which concludes that although clinically, incidence of LIG was more common in female it was not statistically significant maybe because of the ongoing COVID19 pandemic situation. [Table-3]. Prajna et al. ${ }^{18}$ in 1994 in Madurai, found marginally significant increased risk of having these glaucomas in females $(p=0.05)$. We also found result similar result as with Pradhan et al. ${ }^{24}$ who reported female to male ratio of $1.7: 1$. He observed that socio-economic and cultural constraints play a major role leading to neglect and late presentation of cataract in females in region where the study was done. In another study by Rijal $\mathrm{AP}^{25}$ female to male ratio was 1.2:1. In our study also we found that female to male ratio is increased due to socio-economic constraints upon females. 
Jyoti Bhuyan et.al. A clinical study on the incidence and visual outcome after surgical management of lensinduced glaucoma.

\section{AGE DISTRIBUTION:}

In our study we found that lens induced glaucoma was more common in elderly people, particularly in the fifth decade and above with mean age at presentation being 61.54 years. Highest number of cases occurred in the age group 56-70 years (62\%). [Table-4]

Pradhanet $\mathrm{al}^{24}$, found occurrence of LIG in the age range of 40 to 80 years and highest (43.1\%) in the 60 to 69 years age. Occurrence of LIG in the older age group is attributed to the fact that development of cataract is neglected till they become hypermature and produce acute symptoms like pain requiring immediate medical help. This was mainly because of insidious onset of cataract, lack of medical awareness and literacy, lack of regular eye check-up, ignorance and limited resources in developing countries. Similar observations were also made by Saikia $\mathrm{AK}^{17}$. In the study by Murty et $\mathrm{al}^{22}$ (78\%) lens induced glaucoma were seen in the age group of above 50 years. In our study $\mathrm{x} 2=1.407$, pvalue $=0.495$ showing that no significant association existed between the age group of patients and the disease in this study.

Presenting signs and symptoms

Most of the cases of lens induced glaucoma presented with common symptoms. The onset of glaucoma in all of the cases was characterized by pain in and around the eyes with headache of varying intensity of nausea and vomiting. These symptoms were preceded by gradual progressive, painless diminution of vision for months or years. Redness and ciliary congestion were present in all the affected eyes. The presenting symptoms varied in severity and were directly proportional to the degree of rise of intraocular pressure. In phacomorphic group, patients also complained of sudden severe diminution of vision in the affected eye. [Table-7]. Dharet al. ${ }^{26}$ (1984) also reported similar findings to our study with $100 \%$ occurrence of dimness of vision, eye pain and redness of eyes in his series of 214 cases of lens induced glaucoma. Studies by Rohatgi et al. ${ }^{27}$ and Saikia $\mathrm{AK}^{17}$ also reported same findings.

\section{DURATION OF SYMPTOMS}

Majority of the cases in this study 28(56\%), presented with pain and redness within the first week after developing the symptoms. The rest of 22 cases (44\%) presented after 1 week. The mean duration was 8.80 days. In the study by Pradhan et al. ${ }^{24} 70 \%$ of cases presented after 10 days of onset of symptoms citing reasons like 'no escort' and 'lack of money'

In our study, duration of symptoms had a linear relation with best-corrected visual acuity at final follow up. More the delay in presentation, poorer was the visual outcome, which was both clinically and statistically significant $(p=0.0148)$ [Table 19]

\section{SOCIOECONOMIC BACKGROUND:}

Most of the patients who presented with LIG were from rural and semi urban areas and of poor socioeconomic background. It was observed that literacy among the cases was low and many of them were from remote areas without any nearby eye care facility. This is one of the major causes for late presentation in our study.

In the series by Prajna et al ${ }^{18}$ all patients were from higher socio-economic group and belonged to the paying section. Both these series therefore may not reflect the true distribution of characteristics of these glaucomas in the general population.

\section{INTRAOCULAR PRESSURE:}

In our series $64 \%$ of cases presented with IOP of more than $40 \mathrm{~mm}$ of Hg.[Table11]. The mean IOP at presentation in our study was 43.84 with SD of $9.93 \mathrm{mmofHg}$ [Table-9]. Dhar et all ${ }^{26}$ in his study reported mean IOP in the affected eye of $36.6 \mathrm{~mm}$ of $\mathrm{Hg}$ with a standard deviation of $7.4 \mathrm{~mm}$ of $\mathrm{Hg}$ which was lower than that of our study with $9.93 \mathrm{~mm}$ of $\mathrm{Hg}$. The highest recorded intra ocular pressure in the study by Dharet al. ${ }^{26}$ was $60.3 \mathrm{~mm}$ of $\mathrm{Hg}$ which was comparable to our findings. Another 
Jyoti Bhuyan et.al. A clinical study on the incidence and visual outcome after surgical management of lensinduced glaucoma.

conducted by Rangaraj et $\mathrm{al}^{20}$, the mean preoperative IOP was $46.2 \mathrm{~mm}$ of $\mathrm{Hg}$ which is slightly higher than that in our study. The intraocular pressure varied from 25 to $820 \mathrm{of}$ $\mathrm{Hg}$ with a mean of $45.50 \mathrm{~mm}$ of $\mathrm{Hg}$ and showed a progressive rise with the duration of attack in the study by Jain IS et $\mathrm{al}^{28}$. Prajna et al ${ }^{18}$ reported mean preoperative intraocular pressure of $42 \mathrm{~mm}$ of $\mathrm{Hg}$ with a standard deviation of $12 \mathrm{~mm}$ of $\mathrm{Hg}$ in his series.

In our study clinically significant proportion of cases(82.4\%) with IOP at presentation less than $40 \mathrm{mmHg}$ achieved good visual acuity of 6/6-6/12, than cases(66.7\%) with IOP more than $40 \mathrm{~mm}$ Hg, whereas no significant difference was found for poor outcome.[Table-17]

Prajna et al. $^{18}$ reported that no statistically significant association between the level of preoperative IOP and final visual acuity in his study. In $86.27 \%$ [Table-17] of cases in our study, postoperative IOP was less than $20 \mathrm{~mm}$ of Hg which is more than the observations by Pradhan et al. ${ }^{24}$

\section{Response to medical management:}

In our study we found out that raised IOP and inflammation subsided significantly after the administration of topical steroids and anti-glaucoma medication. IOP was controlled by $20 \%$ mannitol, oral glycerol, acetazolamide orally and/or topical timolol maleate in different combinations. Similar observation was also reported by Dhar et $\mathrm{al}^{26}$. In another study by Jain IS, Gupta et $\mathrm{al}^{28}$, intraocular pressure was controlled preoperatively with or without mannitol in all the 86 eyes.

\section{Surgical management:}

In our study out of 29 cases of phacomorphic glaucoma, Combined surgery (SICS+PCIOL+Trabeculectomy) was done for 8 cases. Combined surgery was done in cases with longer duration of attack. SICS with PC IOL was done for remainder of cases of phacomorphic glaucoma cases, with short duration of attack. SICS with
PCIOL with iridectomy is done in 5 cases of phacomorphic glaucoma [Table-14]. Laser iridotomy was done in 1 of the case of phacomorphic glaucoma preoperatively, where IOP was not controlled with maximum medical management.

There were 16 Phacolytic glaucoma cases. SICS with PCIOL was done in 12 of those cases. Triple procedure was performed in 3 cases of phacolytic glaucoma and SICS+PCIOL+Iridectomy was done in 1 of the cases. Out of the three cases of lens particle glaucoma 2 were surgically managed with small incision cataract surgery with posterior chamber IOL implantation 1 with triple procedure. Also, the 2 phacoanaphylactic glaucoma cases were treated by combination of oral and topical steroid. After the symptoms were relieved, cataract operation with PCIOL was performed. [Table-14]

Prajna et al $^{18}$ subjected all the patients to a traditional planned ECCE. A decision to implant a posterior chamber IOL was taken on those whose fellow eye was or which had a clear lens or very early lens changes, and those who insisted on having an IOL implant. A peripheral iridectomy was performed on all the patients.

In another study by Pradhan et $\mathrm{al}^{24}$ the 311 cases underwent scleral tunnel suture less cataract surgery; 191 (61.4\%) had ECCE without PCIOL and 102 (32.8\%) received a +21D PCIOL. An ICCE was done in 17 (5.5\%) patients; one of these patients (0.3\%) received an ACIOL.

In our series we managed to do suture less cataract surgery in all the cases. Pre-operative IOP control in all those cases were achieved medically to acceptable limits before going for definitive surgery.

\section{Best corrected visual acuity (BCVA) and its association with Age, IOP and duration of symptoms at presentation}

BCVA of $6 / 12$ or better was considered as good visual acuity and $6 / 18$ or less as poor visual outcome.

In our study, out of 50 cases, (32\%) cases presented with only perception of light 
Jyoti Bhuyan et.al. A clinical study on the incidence and visual outcome after surgical management of lensinduced glaucoma.

and $64 \%$ with hand movements close to face and $4 \%$ with doubtful perception of light [Table-12]

$38 \%$ of cases in our study achieved best corrected visual acuity of $6 / 9$ and $28 \%$ achieved 6/12 visual acuity at the end of final follow up at 6 weeks. $10 \%$ cases achieved visual acuity between of $6 / 18$ and $36 \%$ regained visual acuity less than 6/24.[Table-16]

The cause of poor visual outcome in the cases of our series was attributed to late presentation leading to glaucomatous damage of the optic nerve head (ONH) in 5 of the cases which was characterized by increased Cup to disc ratio. In 6 cases of Proliferative and Non-proliferative diabetic retinopathy also contributed to the glaucomatous damage to produce poor vision.

In this series, BCVA of $6 / 12$ or better is higher (58.82\%) than observed by Pradhan et $\mathrm{al}^{24}$. (31.40 \%) and Gupta et $\mathrm{al}^{28}$ (24\%) but is comparable to Prajna et at ${ }^{17}$. (59.12\%) and less than that observed by Murty et al. ${ }^{22}(80 \%) .28 \%$ of cases in our study achieved moderately better vision between 6/18-6/60 which is higher than Murty et al. $^{22}$ (10\%) and less than that observed by Rijal et $\mathrm{al}^{25}$. (40\%). BCVA in our series was better than that by Pradhan et $\mathrm{al}^{24}$. Might be because the large sample size in that study $(n=413)$ than ours $(n=50)$. And more importantly $71 \%$ patients presented after 10 days in their series. In all case, we were able to do PCIOL implantation which factored in better visual outcome in our series. Also we were able to motivate patients to come for two follow up visits in $100 \%$ cases unlike in the series by Pradhan et $\mathrm{al}^{24}$ wherein spite of motivating the operated patients and offering monetary incentives, the follow-up rate was low. Only 105 patients (33.8\%) reported for follow-up 4 - 12 weeks after surgery.

\section{Association between Age and final BCVA}

In this study [Table-18], 4 cases of age less than 50 years and 32 cases of age more than 50 years achieved good visual acuity of better than $6 / 18$. We observed that there was no statistically significant association between age at presentation and BCVA ( $\mathrm{P}$ value $=0.675$, OD-1.625, $95 \%$ CI -0.166-15.96). Marginally significant risk of poor visual outcome was observed in cases of age higher than 60 years when compared with younger patients by Prajna et $\mathrm{a}^{18}$ (OR=2.7, 95\%CI=1.04 -6.93).

\section{Association between duration of symptoms and BCVA}

In this study (Table-19), $85.7 \%$ of cases presenting earlier than 7 days, regained good visual outcome. Whereas only $54.5 \%$ of cases presenting beyond 7 days achieved good visual acuity of 6/12 or better. It showed that a significant risk of poor visual acuity was found when the duration between the onset of symptom and presentation to our OPD was more than 7 days $(\mathrm{p}$ value $=0.0148$; OR-5.00; $95 \%$ CI 1.295-19.31). Similar observation was made by Prajna et al ${ }^{18}$ where a significant risk of poor visual acuity was found when the duration between the onset of pain and surgery exceeded five days.

\section{Association between IOP and BCVA}

In our study, 82.4\% [Table-17] of cases with IOP at presentation less than $40 \mathrm{mmlHg}$ achieved good visual acuity, whereas cases with IOP more than $40 \mathrm{~mm}$ $\mathrm{Hg}$ i.e. $66.7 \%$ achieved good visual outcome. The correlation between preoperative IOP and visual outcome was, clinically significant but statistically not significant ( $\mathrm{p}$ value $=0.252 ; \mathrm{OR}=2.33,95 \%$ $\mathrm{CI}=0.552-9.866$ ). Madurai study (Prajna et $\mathrm{al}^{18}$ ) also had found no statistically significant association between the level of preoperative IOP and final visual acuity. ( $\mathrm{p}$ value $=0.07$ )

\section{CONCLUSION}

From our study we can draw the following conclusions

- A cataractous lens can produce an important 
Jyoti Bhuyan et.al. A clinical study on the incidence and visual outcome after surgical management of lensinduced glaucoma.

complication like lens-induced glaucoma and it can be of varied types.

- Diminution of vision, eye pain and redness are the main clinical presentation of LIG where extraction of the cataractous lens results in immediate reduction in IOP with a favourable visual outcome.

- The mainstay to prevent LIG is early diagnosis and treatment of cataract. Since delayed treatment of lens-induced glaucoma may result in poor visual outcome.

- Health education about regular eye checkup and prompt management of cataract is of utmost importance for a better visual outcome and to prevent complications like lens induced glaucoma. The role of community outreach programmes like eye-camps is an important tool for disease detection and a healthy community management in a developing country like India.

\section{Acknowledgement: None}

\section{Conflict of Interest: None}

\section{Source of Funding: None}

\section{Ethical Approval: Approved}

\section{REFERENCES}

1. DadaT, Ichhpujan $P, \quad$ Lingam V,Ramaswamik, Kaushiks, VyasP, SarmaP. Guidelines for medical management of primary open angle glaucoma. All India ophthalmological society.2011;p6

2. Shields textbook of glaucoma, 6th edition

3. Jose R. Present Status of the National Programme for Control of Blindness in India. Community Eye Health J. 2008; 21(65):103-4.

4. Dandona L, Dandona R, Mandal P, Srinivas M, John RK, McCarty CA, et al . "Angleclosure glaucoma in an urban population in southern India: The Andhra Pradesh eye disease study". Ophthalmology 2000; 107:1710-6

5. Dandona L, Dandona R, Srinivas M, Mandal P, John RK, McCarty CA, et al . "Open-angle glaucoma in an urban population in southern India: The Andhra Pradesh eye disease study". Ophthalmology 2000;107:1702-9

6. Vijaya L, George R, Arvind H, Baskaran M, Raju P, Ramesh SV, Paul PG, Kumaramanickavel G, McCarty C. Prevalence and causes of blindness in the rural population of the Chennai Glaucoma Study. Br J Ophthalmol. 2006 Apr;90(4): 407-10. doi: 10.1136/bjo.2005.081406. PMID: 16547314; PMCID: PMC1857022.

7. Ramakrishnan R, Nirmalan PK, Krishnadas R, Thulasiraj RD, Tielsch JM, Katz J, et al. "Glaucoma in a rural population of southern India: The Aravind Comprehensive Eye Survey". Ophthalmology 2003;110:148490.

8. National programme for control of blindness (NPCB), Director General of Health and Family Welfare, Govt. of India.

9. Dr Manish Pande, Dr Ronnie Jacob George, Dr Lingam Vijaya. Chapter "Glaucoma in India". Glaucoma Diagnosis And Management Pathways. page:3

10. Paul F. Palmberg, Joney L Wiggs: mechanism of glaucoma, 1423, Vol 2. Ophthalmology: Yanoff, Duker

11. Gifford H: "Danger of spontaneous cure of senile cataracts" Am J Ophthalmology $1900,17,289$

12. Kanski clinical ophthalmology, 7th edition

13. Ellant JP, Ostbaum SA Lens-induced glaucoma. Doc Ophthalmologica 1992; 81:317-38

14. Ministry of Health and Family Welfare: Problem of blindness in India In: Status of National Program for Control of Blindness (NPCB). Government of India, New Delhi 1993:2.

15. Minassian DC, Mehra U. 3.8 million blinded by cataract each year: projection from the first epidemiological study of incidence of cataract in India. $\mathrm{Br} \mathrm{J}$ Ophthalmol 74:341- 343, 1990

16. Fletcher A, Thulasiraj RD, et al. Low uptake of eye services in rural India: A challenge for programs of blindness prevention. Arch Ophthalmol. 1999,117:1393-1399

17. Saikia AK: A clinical study on lens induced glaucoma: A thesis submitted to Gauhati University in 1992

18. Prajna NV, Ramakrishnan R, Krishnadas R, Manoharan N. Lens induced glaucomas visual results and risk factors for final visual acuity Indian J Ophthalmol 1996; 44:149-55 
Jyoti Bhuyan et.al. A clinical study on the incidence and visual outcome after surgical management of lensinduced glaucoma.

19. Saikia SP. "Clinical study on lens induced glaucoma": Thesis is submitted to Gauhati University in 1999.

20. Venkatesh, R., Tan, C. S. AL., Kumar, T. T., \&Ravindran, R. D. (2007). Safety and efficacy of manual small incision cataract surgery for phacolyticglaucoma The British Journal of Ophthalmology, 91(3), 279-281.

21. Kothari et. al. Lens-Induced Glaucoma: The Need to Spread Awareness about Early Management of Cataract among Rural Population. ISRN Ophthalmology Volume 2013 (2013)

22. Murty et al. A Clinical Study of Lens Induced Glaucoma. International Journal of scientific research and management (IJSRM). 2015

23. DuttaL.C,BaruahC.K,Sarma BK Paper submitted to congress of Asia Pacific Academy of Ophthalmology, 1985, New Delhi.

24. Pradhan D. Hennig A, Kumar J, Foster A., A prospective study of 413 cases of lensinduced glaucoma in Nepal. Indian $\mathrm{J}$ Ophthalmol. 2001 Jun;49(2):103-7.

25. Rijal AP, Karki DB. Visual outcome and TOP control after cataract surgery in lens induced glaucomas, Kathmandu University Medical Journal (2006), Vol.4, No. 1, Issue 13, 30-33.

26. Dhar G L, Bagotra S, Bhalla A. Lens induces glaucoma-a clinical study. Indian J Ophthalmol 1984; 32:456-9

27. Rohatgi JN. Lens induced glaucoma. A clinical study. Indian J Ophthalmol 1972; 20:88-93

28. Jain IS, Gupta A, Dogra MR, Gangwar DN, Dhir SP. Phacomorphic glaucomamanagement and visual prognosis. Indian J Ophthalmol. 1983 Sep;31(5):648-53. PMID: 6671784.

29. Gupta P, Bhagotra S, Prakash S. Pattern and Visual Outcome in Lens Induced Glaucoma Vol. 14 No. 4, Oct-December 2012 http://www.jkscience.org/

How to cite this article: Bhuyan J, Baishyakh P. A clinical study on the incidence and visual outcome after surgical management of lensinduced glaucoma. Gal Int $J$ Health Sci Res. 2021; 6(4): 42-53. DOI: https://doi.org/10. 52403/gijhsr.20211007 